\title{
Food and Water Consumption Character Result in Standard Format
}

National Cancer Institute

\section{Source}

National Cancer Institute. Food and Water Consumption Character Result in Standard Format. NCl Thesaurus. Code C119839.

The standard character or string for representation and reporting of food and water consumption data. 